\title{
SÉANCE DU 22 NOVEMBRE 1918
}

\author{
Présidence de M. P.-A. Dangeard.
}

Lecture est donnée du procès-verbal de la précédente séance, dont la rédaction est adoptée.

M. F. Camus analyse ensuite assez longuement le travail suivant de MM. Evrard et Chermezon.

\section{La végétation de la Haute-Tarentaise}

\author{
PAR MM. F. EVRARD BT H. CHERMEZON.
}

La Haute-Tarentaise correspond à peu près à la partie supérieure du bassin de l'Isère située en amont de Sainte-Foy; il ne sera pas question ici de la région qui s'étend entre SainteFoy et la Savine; nos explorations ont été en effet limitées au Nord par le bois de la Balme, se tenant toutes par conséquent à une altitude supérieure à 1500 mètres.

Dans toute cette partie de son cours, l'Isère, sortie vers 2400 mètres du glacier de la Galise, a un caractère torrentiel et coule dans des gorges resserrées, séparées par les paliers de Val-d'Isère $(1850 \mathrm{~m}$.), de Tignes $(1650 \mathrm{~m}$.) et des Brévières (1 $570 \mathrm{~m}$.), où la vallée s'élargit un peu; elle est grossie par de nombreux torrents, dont les principaux sont, à droite le torrent de la Sassière, à gauche les torrents de l'Iseran, du Manchet, du lac de Tignes et de la Sachette; ces torrents occupent des vallées secondaires souvent élevées et se raccordant avec la principale par une brusque dénivellation; quelques-unes de ces vallées renferment de petits lacs, dont les plus importants sont le lac de la Sassière $(2446 \mathrm{~m}$.) et le lac de Tignes $(2088 \mathrm{~m}$.).

Tous les massifs atteignent de fortes altitudes et présentent le plus souvent un développement de glaciers assez considé- 


\section{$2 \mathrm{BHL}$ Biodiversity Heritage Library}

1918. "Séance Du 22 Novembre 1918." Bulletin de la Société botanique de France 65, 153-153. https://doi.org/10.1080/00378941.1918.10836068.

View This Item Online: https://www.biodiversitylibrary.org/item/8685

DOI: https://doi.org/10.1080/00378941.1918.10836068

Permalink: https://www.biodiversitylibrary.org/partpdf/159711

\section{Holding Institution}

Missouri Botanical Garden, Peter H. Raven Library

\section{Sponsored by}

Missouri Botanical Garden

\section{Copyright \& Reuse}

Copyright Status: Public domain. The BHL considers that this work is no longer under copyright protection.

This document was created from content at the Biodiversity Heritage Library, the world's largest open access digital library for biodiversity literature and archives. Visit BHL at https://www.biodiversitylibrary.org. 